\title{
ANALISIS GAYA BAHASA PERBANDINGAN PADA ASPEK SIMILE DALAM NOVEL MARMUT MERAH JAMBU KARYA RADITYA DIKA
}

\author{
Youngky Prasetya ${ }^{1}$, Erlina Zahar ${ }^{2}$, Harbeng Masni ${ }^{3}$ \\ Program Studi Pendidikan Bahasa dan Sastra Indonesia, \\ Fakultas Keguruan dan Ilmu Pendidikan, Universitas Batanghari, \\ Jambi \\ yongkiprasetiya123@gmail.com \\ erlina_zahar@yahoo.co.id \\ harbeng.masni@yahoo.com
}

\begin{abstract}
This research is aimed at describing figurative language in simile aspect in the Novel Marmut Merah Jambu by Raditya Dika. This research is qualitative descriptive. The data of this research is primary and secondary data. The primary data is taken directly while secondary data is taken from books, notes, and certain evidence, or published or unpublished archives. The result of the researc identifies that there are 8 quotes of figurative language in simile aspect which is found in the novel Marmut Merah Jambu by Raditya dika.
\end{abstract}

Kata Kunci: analisys, figurative language, novel

\footnotetext{
${ }^{1}$ Mahasiswa Program Studi Pendidikan Bahasa dan Sastra Indonesia, Fakultas Keguruan dan Ilmu Pendidikan Universitas Batanghari, Jambi

${ }^{2}$ Dosen Program Studi Pendidikan Bahasa dan Sastra Indonesia, Fakultas Keguruan dan Ilmu Pendidikan Universitas Batanghari, Jambi

${ }^{3}$ Dosen Program Studi Pendidikan Bahasa dan Sastra Indonesia, Fakultas Keguruan dan Ilmu Pendidikan Universitas Batanghari, Jambi
} 
PENDAHULUAN

Gaya bahasa merupakan ungkapan penulis terhadap karyanya yang dapat mengungkapkan ekspresi serta imajinasinya kepada pembaca dan pendengar. Gaya bahasa diperlukan oleh penulis karya sastra untuk mengungkapkan pemikirannya dalam sebuah cerita. Salah satu karya sastra yang menggunakan ragam gaya bahasa adalah novel.

Cerita dalam novel tentunya bervariasi. Isi cerita dalam novel tentu terdapat penggunaan gaya bahasa di dalamnya, misalnya gaya bahasa pertautan, pertentangan, dan perbandingan. Novel merupakan bentuk karya sastra yang banyak dinikmati oleh kalangan masyarakat, terutama kalangan remaja. Hal ini penulis ketahui dari antusiasme remaja yang banyak mencari novel keluaran terbaru di toko-toko buku.

Remaja-remaja saat ini banyak menikmati novel karena pada umumnya novel lebih dominan menceritakan persoalan kehidupan remaja. Inilah salah satu penyebab tingginya minat remaja terhadap novel.

\section{Dika Angkasaputra Moerwani} atau yang lebih dikenal dengan Radtiya Dika merupakan seorang yang multitalenta. Dia adalah seorang penulis dan juga sebagai komika stand up comedy. Selain itu, Radit juga melakoni profesi sebagai sutradara dan aktor. Saat ini Radit telah menciptakan 10 karyanya dalam bentuk buku. Tujuh diantaranya berbentuk novel dan tiga berbentuk komik yang ia ciptakan bersama Adriano Rudiman.

Novel Marmut Merah Jambu Karya Radtiya Dika ini termasuk novel yang paling banyak digemari pembaca, khususnya penggemar Radit. Selain itu, dengan ciri khas gaya bahasa yang digunakan Radit dapat menjadikan pembaca atau penikmat novel ini menjadi terhibur. Penggunaan gaya bahasa dalam novel ini dapat memudahkan pembaca memahami makna cerita yang terkadung di dalamnya.

Penelitian ini hanya difokuskan pada analisis gaya bahasa perbandigan pada aspek simile dalam Novel Marmut Merah Jambu, berdasarkan fokus penelitian di atas, maka pertanyaan penelitian ini adalah, Bagaimanakah penggunaan gaya bahasa perbandingan pada aspek simile dalam novel Marmut Merah Jambu Karya Raditya Dika?

Novel merupakan karangan prosa tentang masyarakat yang dilukiskan dengan berbagai puncak peristiwa. "Novel adalah karangan yang dihasilkan 
dari kreatifitas dan imajinasi pengarang tetapi tidak terlepas dari kehidupan nyata dan nilai-nilai kehidupan" (Nurgiyantoro, 2009:9). Pendapat Nurgiyantoro di atas menggambarkan bahwa novel dihasilkan berdasarkan fenomena yang dialami oleh pengarang tentang proses kehidupan manusia.

Novel merupakan jenis karya sastra sastra baru. "Kata novel berasal dari bahasa latin, kata novellus dibentuk dari kata novus yang berarti baru atau new dalam bahasa inggris. Dikatakan baru karena "Novel adalah bentuk karya sastra yang datang kemudian setelah bentuk karya sastra lainnya, yaitu puisi dan drama." (Priyatni, 2010:124).

Novel merupakan karya fiksi yang memiliki unsur pembangun yaitu berupa unsur intrinsik dan unsur ekstrinsik. Kepaduan kedua unsur inilah yang menjadikan sebuah novel menarik untuk dibaca.

Unsur Instinsik adalah unsurunsur yang membangun sebuah karya sastra. Unsur intrinsik dalam sebuah novel adalah unsur-unsur yang secara langsung turut membangun cerita."Unsur intrinsik adalah unsur yang membangun karya sastra itu sendiri. Unsur-unsur inilah yang menyebabkan hadirnya karya sastra. Unsur-unsur yang secara faktual akan dijumpai jika orang membaca karya sastra" (Nurgiyantoro, 2009: 23).

Unsur ekstrinsik merupakan unsur pembangun dari luar karya sastra."Unsur ekstrinsik adalah unsur-unsur yang berbeda di luar karya sastra itu, tetapi secara tidak langsung mempengaruhi pembangun atau sistem organisme karya sastra" (Nurgiyantoro, 2009: 23). Unsur ekstrinsik akan membantu dalam pemahaman makna karya sastra itu sendiri.

1. Nilai Budaya

Nilai Budaya merupakan adat istiadat yang terdapat dalam setiap daerah. Setiap daerah memiliki adat istiadat yang berbeda-beda. "Nilai budaya berkaitan dengan pemikiran, kebiasaan, dan hasil karya cipta manusia" (Kosasih, 2012: 3). Nilai budaya juga dapat dikatakan sebagai aturan-aturan yang ada di dalam lingkungan masyarakat.

\section{Nilai Moral}

Nilai moral merupakan nilai dalam cerita yang berkaitan dengan akhlak, perangai atau etika sesorang dalam berinteraksi dengan manusia. "Nilai moral adalah sistem nilai tentang motivasi, perilaku dan perbuatan tertentu dinilai baik dan buruk" (Elmubarok, 
2008: 27). Moral dalam karya sastra biasanya mencerminkan pandangan hidup pengarang. Moral dalam karya sastra menggambarkan nilai-nilai kebenaran yang disampaikan kepada pembaca.

\section{Nilai Sosial}

Nilai sosial adalah gejala perilaku masyarakat yang berperan penting untuk mendorong dan maengarahkan individu sesuai norma yang berlaku. "Nilai sosial berkaitan dengan tata laku hubungan antara sesama manusia (kemasyarakatan)" (Kosasih, 2012: 3). Nilai sosial merujuk pada hubungan antara manusia dan masyarakat.

4. Nilai Agama

Nilai agama merupakan ketentuan hidup yang harus diterima oleh manusia sebagai perintah dan larangan yang bersumber dari Tuhan Yang Maha Esa. "Agama adalah seperangkat sistem norma yang mengatur hubungan manusia dengan Tuhanya, manusia dengan sesama manusia, dan manusia dengan alam sekitarnya" (Mulyadi dkk, 2012: 49). Dengan demikian, kehidupan sehari-hari manusia berpedoman pada agama. Nilai agama menjadikan manusia berakhlak mulia.

Gaya bahasa merupakan cara yang khas yang digunakan seseorang untuk mengungkapkan cerita. "Gaya bahasa merupakan sesuatu pembentuk gaya” (Priyatni,2012: 114).

Pengungkapan bahasa dalam novel mencerminkan sikap dan perasaan pengarang yang dapat digunakan untuk mempengaruhi sikap dan perasaan pembaca. Untuk itu, bentuk pengungkapkan bahasa harus efektif dan mampu mendukung gagasan secara tepat yang memiliki nilai estetis sebagai sebuah tulisan. Kekhasan, ketepatan dan kebaruan, pemilihan bentuk-bentuk pengungkapan bahasa dan gagasan sangat menentukan keefektifan sebuah tulisan yang dihasilkan. Salah satu bentuk tulisan yang sangat mementingkan pengungkapan bahasa ialah novel.

Seperti yang telah dijelaskan dalam subbab sebelumnya, bahwa gaya bahasa merupakan salah satu bagian dari unsure intrinsik yang membangun sebuah novel. "Gaya bahasa adalah bahasa indah yang digunakan untuk meningkatkan efek dengan jalan memperkenalkan serta membandingkan suatu benda atau hal tertentu dalam benda atau hal lain yang lebih umum. Secara singkat penggunaan gaya bahasa tertentu dapat mengubah serta menimbulkan konotasi tertentu" (Dale dalam Tarigan, 2009:4). Selanjutnya diungkapkan oleh 
ahli lain bahwa "Secara singkat dapat dikatakan bahwa gaya bahasa adalah cara mengungkapkan pikiran melalui bahasa secara khas yang memperlihatkan jiwa dan kepribadian penulis" (Keraf, 2002: 113).

Gaya bahasa yang digunakan oleh sastrawan, meskipun tidak terlalu luar biasa, namun unik karena selain dekat dengan watak dan jiwa penyair juga membuat bahasa yang digunakannya berbeda dalam makna dan kemesraanya. Dengan demikian, gaya bahasa lebih merupakan pembawaan pribadi. Gaya bahasa dipakai pengarang hendak memberi bentuk terhadap apa yang ingin disampaikan. Dengan gaya bahasa tertentu pula seorang pengarang dapat mengekalkan pengalaman rohaninya dan penglihatan batinnya, serta dengan itu pula menyentuh hati pembacanya. "Gaya bahasa dapat dikatakan sebagai cara mengungkapkan pikiran melalui bahasa secara khas yang memperlihatkan jiwa dan kepribadian penulis (pemakai bahasa)" (Keraf, 2010:113).

"Gaya bahasa dapat dikategorikan dalam berbagai macam, lain penulis lain pula klasifikasi yang dibuatnya. Gaya bahasa yang berbagai macam itu dibagi menjadi kelompok yaitu (1) gaya bahasa perulangan, (2) gaya bahasa pertentangan, (3) gaya bahasa pertautan, (4) gaya bahasa perbandingan" (Tarigan, 2009:5). Berdasarkan macam-macam gaya bahasa di atas, maka penulis hanya meneliti gaya bahasa perbandingan saja. Jadi gaya bahasa yang diteliti dalam penelitian ini adalah gaya bahasa perbandingan pada aspek simile.

Menurut Keraf (2009:113), gaya bahasa yang baik harus mengandung tiga unsur antara lain kejujuran, sopan-santun dan menarik. Berikut akan dijelaskan tentang ketiga unsur tersebut.

a. Kejujuran

Kejujuran adalah suatu pengorbanan, karena kadang-kadang ia meminta kita melaksanakan sesuatu yang tidak menyenangkan diri kita sendiri. Kejujuran dalam bahasa berarti kita mengikuti aturan-aturan, kaidah-kaidah yang baik dan benar dalam berbahasa.

b. Sopan-santun

Sopan santun adalah memberi penghargaan atau menghormati orang yang diajak bicara, khususnya pendengar atau pembaca. Rasa hormat disini tidak berarti memberikan penghargaan atau menciptakan kenikmatan melalui katakata atau mempergunakan kata-kata yang manis sesuai dengan basa-basi dalam pergaulan masyarakat beradab.

c. Menarik 
"Sebuah gaya bahasa yang menarik dapat diukur melalui beberapa komponen berikut: variasi, humor yang sehat, pengertian yang baik, tenaga hidup (vitalitas), dan penuh daya khayal (imajinasi)" (Keraf, 2009:115).

Gaya bahasa perbandingan adalah gaya bahasa yang dipakai untuk membandingkan sesuatu dengan yang lainnya. Perbandingan sebenarnya mengandung dua pengertian, yaitu perbandingan yang termasuk dalam gaya bahasa yang polos dan langsung dan perbandingan yang termasuk dalam gaya bahasa kiasan (Keraf, 2010:136).

Gaya bahasa perbandingan merupakan gaya bahasa yang mempunyai karakteristik untuk membedakan atau menyamakan dalam melukiskan sesuatu hal dengan jalan membandingkan dengan suatu hal yang lain.

Persamaan atau simile adalah perbandingan yang bersifat eksplisit. eksplisit ialah bahwa ia langsung menyatakan sesuatu yang sama dengan hal lain. "Simile adalah perbandingan dua hal yang pada hakikatnya berlainan dan sengaja kita anggap sama" (Tarigan, 2009:9).

Hal ini sesuai dengan pendapat Tarigan yang menyebutkan bahwa "Simile adalah perbandingan yang bersifat eksplisit yaitu menyatakan secara langsung hal yang sama dengan menggunakan kata-kata seperti, sama, sebagai, bagaikan, laksana, dan sebagainya" (Keraf, 2010:138).

Contoh :Bibirnya seperti merah delima.

\section{METODE PENELITIAN}

Metode penelitian merupakan cara dalam sebuah penelitian untuk mencapai tujuan penelitian yang diinginkan. "Metode penelitian pada dasarnya merupakan cara ilmiah untuk mendapatkan data dengan tujuan dan kegunaan tertentu." (Sugiyono, 2013: 2).

Jenis penelitian ini ialah penelitian kualitatif. Penelitian ini menggunakan pendekatan deskriptif. Penelitian kualitatif dapat diartikan sebagai penelitian yang menghasilkan data deskriptif mengenai kata-kata lisan maupun tertulis, dan tingkah laku yang dapat diamati.

Data primer merupakan data yang didapat secara langsung. "Data primer adalah data utama, yaitu data yang diseleksi atau diperoleh langsung dari sumbernya tanpa perantara" (Siswantoro, 2010:70). Data primer dalam penelitian ini yaitu berupa gaya bahasa perbandingan dalam novel Marmut Merah Jambu karya Raditya Dika. 
Selain data primer, dalam penelitian ini juga dibutuhkan data sekunder. "Data sekunder adalah data yang diperoleh secara tidak langsung atau lewat perantara, tetapi tetap kepada kategori atau parameter yang menjadi rujukan" (Siswantoro, 2010:71). Data sekunder dalam penelitian ini diperoleh melalui buku penunjang yang berkaitan langsung dengan unsur intrinsik karya sastra yaitu seperti buku tentang sastra yang membahas kajian gaya bahasa perbandingan.

"Sumber data adalah subjek darimana dapat diperoleh" (Arikunto, 2010:172). Sumber data dalam penelitian ini adalah novel Marmut Merah Jambu karya Raditya Dika, cetakan ke 30 tahun 2014 yang diterbitkan oleh Bukune. Sampul berwarna putih, merah, cokelat, dan hijau. Dengan ilustrasi gambar Raditya Dika sendiri yang bergaya layaknya marmut serta dikelilingi ilustrasi gambar handphone, laptop, kalender, surat dan botol. Jumlah halaman 222 . Ukuran buku $13 \times 20 \mathrm{~cm}$. Selain novel tersebut, sumber data lainnya yaitu berupa buku-buku yang penulis dapatkan dari berbagai sumber Teknik pengumpulan data merupakan cara-cara yang digunakan dalam mengumpulkan data. Teknik pengumpulan data dipilih sesuai dengan tujuan dan fokus masalah dalam sebuah penelitian, sehingga mempermudah peneliti dalam menemukan data yang diperlukan.

“Teknik pengumpulan data merupakan langkah yang paling strategis dalam penelitian, karena tujuan utama dari penelitian adalah mendapatkan data" (Sugiyono, 2013:224). Tanpa adanya teknik pengumpulan data, peneliti tidak akan mendapatkan data yang ditetapkan. Teknik pengumpulan data yang digunakan dalam penelitian ini adalah sebagai berikut.

1. Studi pustaka merupakan pengumpulan data berdasarkan literatur-literatur yang berkaitan dengan penelitian. Teknik ini digunakan untuk mencari teori-teori tentang gaya bahasa, novel, ataupun literature lain. Teori yang didapat dijadikan pijakan untuk menganalisis data yang telah dikumpulkan.

2. Dokumentasi merupakan catatan peristiwa yang sudah berlalu. Dokumentasi bisa berbentuk tulisan, gambar, atau karya-karya monumental dari seseorang (Sugiyono, 2012:329). Dokumentasi digunakan untuk mengumpulkan data-data penelitian pada Novel 
Marmut Merah Jambu karya Raditya

Dika.

3. Peneliti menandai objek penelitian dan mencatat bagian-bagian gaya bahasa perbandingan yang terdapat dalam novel Marmut Merah Jambu karya Raditya Dika,

4. Peneliti mengelompokkan data sesuai dengan jenis-jenis gaya bahasa perbandingan yang terdapat dalam novel Marmut Merah Jambu karya Raditya Dika.

5. Mengidentifikasi data yang mengandung gaya bahasa perbandingan yang terdapat dalam novel Marmut Merah Jambu karya Raditya Dika.

6. Mengklasifikasikan data yang terdapat gaya bahasa perbandingan dalam novel Marmut Merah Jambu karya Raditya Dika.

"Teknik analisis data dilakukan dengan pemaparan dalam bentuk deskriptif terhadap masing-masing data secara fungsional dan relasional (Siswantoro, 2010:81). Kegiatan anlisis data penelitian ini dilakukan dengan langkah-langkah sebagai berikut:

1. Data yang sudah diklasifikasikan pada teknik pengumpulan data, kemudian dimasukkan ke dalam tabel tabulasi data.
2. Peneliti menganalisis sesuai dengan gaya bahasa perbandingan yang dianalisis dalam novel Marmut Merah Jambu karya Raditya Dika.

3. Peneliti mendeskripsikan hasil dan analisis sesuai dengan gaya bahasa perbandingan dalam novel Marmut Merah Jambu karya Raditya Dika.

4. Triangulasi data.

5. Peneliti merumuskan dan menarik suatu kesimpulan.

\section{HASIL DAN PEMBAHASAN}

Berdasarkan hasil analisis yang sudah peneliti lakukan, ternyata dalam novel Marmut Merah Jambu ini terdapat 8 kutipan mengenai gaya bahasa perbandingan pada aspek simile. Berikut dijabarkan kutipan-kutipan tersebut.

\section{Kutipan-kutipan Gaya Bahasa Persamaan/ Simile dalam Novel Marmut Merah Jambu karya Raditya Dika}

Gaya bahasa perbandingan jenis persamaan/simile dalam novel Marmut Merah Jambu karya Raditya Dika terdapat sebanyak 8 kutipan.

Kutipan 1

Misalnya: kalau kamu jadi lebah, gue mau jadi madunya." Atau yang lebih parah, "Kalau kamu jadi lebah, gue mau jadi sepedanya. (Raditya: 6)

Kutipan 2 
Orang yang jatuh cinta diam-diam selalu bertingkah seperti seorang penguntit. (Raditya: 6)

\section{Kutipan 3}

Seperti yang ditulis oleh Oscar Wilde: seperti dua kapal yang berpapasan sewaktu badai, kita telah bersilang jalan satu sama lain; tapi kita tidak membuat sinyal. (Raditya: 7)

Kutipan 4

Widya adalah kapal, sedangkan Aldi adalah singa laut yang kepalanya bocor ditabrak kapal tersebut. Lalu si singa laut mati ngambang di tengah lautan luas. (Raditya: 7)

\section{Kutipan 5}

Nasib punya suara seperti Doraemon yang belum akil balig. (Raditya: 9)

Kutipan 6

Tarian gue secara tidak sengaja mirip dengan tarian pemanggil hujan. (Raditya: 13)

Kutipan 7

Senior-senior memanggil gue dengan nama itu karena muka gue mirip muka yang ada di kartun-kartun. (Raditya: 60)

Kutipan 8

Filosofinya Indonesianya sederhana, jika cinta bisa membuat tahi jadi rasa cokelat, cinta yang tak berbalas bisa membuat cokelat jadi rasa tahi. (Raditya: 92)

\section{SIMPULAN}

Berdasarkan hasil penelitian analisis gaya bahasa dalam Novel Marmut Merah Jambu karya Raditya Dika, dapat disimpulkan bahwa terdapat 8 kutipan mengenai gaya bahasa perbandingan pada aspek simile. Hasil penelitian ini juga menyimpulkan bahwa gaya bahasa perbandingan tersebut didominasi oleh penggunaan kata perbandingan seperti.

\section{DAFTAR PUSTAKA}

Arikunto, Suharsimi. (2010). Prosedur Penelitian Suatu Pendekatan Praktis. Jakarta: Rineka Cipta.

Keraf, Gorys. (2010). Diksi dan Gaya Bahasa. Jakarta: Gramedia Pustaka Utama.

Kosasih, E. (2012). Apresiasi Sastra Indonesia. Jakarta: Nobel Edumedia.

Nurgiyantoro, Burhan. (2009). Teori Pengkajian Fiksi. Yogyakarta: Penerbit Universitas Gajah Mada. Priyatni, Endah Tri. (2010). Membaca Sastra dengan Ancangan Literasi Kritis. Jakarta: Bumi Aksara. 
Priyatni, Endah Tri. (2012). Membaca

Sastra dengan Ancangan Literasi

Kritis. Jakarta: Penerbit Grasindo.

Siswantoro. (2010). Metode Penelitian

Sastra. Yogyakarta: Pustaka

Belajar. 